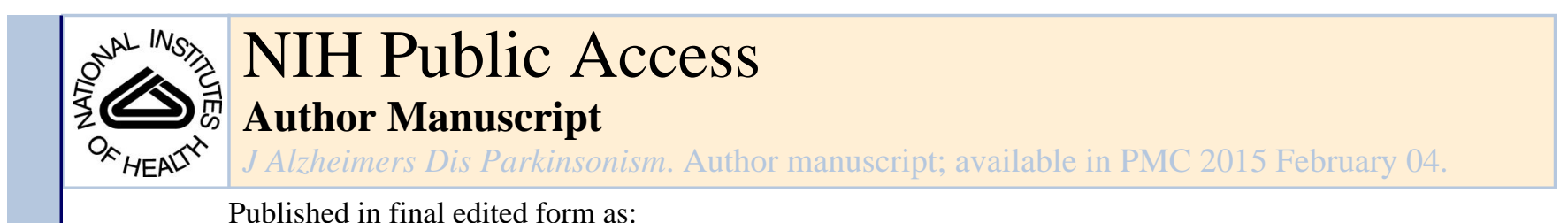

Published in final edited form as:

J Alzheimers Dis Parkinsonism. 2014 November ; 4(5): . doi:10.4172/2161-0460.1000160.

\title{
The Role of TREM2 in Alzheimer's Disease and Other Neurological Disorders
}

\author{
Faris Yaghmoor ${ }^{1}$, Ahmed Noorsaeed ${ }^{2}$, Samar Alsaggaf ${ }^{1}$, Waleed Aljohani ${ }^{1}$, Henrieta \\ Scholtzova ${ }^{1}$, Allal Boutajangout ${ }^{1,3,4,5}$, and Thomas Wisniewski ${ }^{1,2,3,{ }^{*}}$ \\ ${ }^{1}$ Departments of Neurology, New York University School of Medicine, Alexandria ERSP, 450 East \\ 29th Street, New York, NY 10016, USA \\ 2Pathology, New York University School of Medicine, Alexandria ERSP, 450 East 29th Street, \\ New York, NY 10016, USA \\ ${ }^{3}$ Psychiatry, New York University School of Medicine, Alexandria ERSP, 450 East 29th Street, \\ New York, NY 10016, USA \\ ${ }^{4}$ Physiology and Neuroscience, New York University School of Medicine, Alexandria ERSP, 450 \\ East 29th Street, New York, NY10016, USA \\ ${ }^{5}$ King Abdulaziz University, School of Medicine, Jeddah, Saudi Arabia
}

\begin{abstract}
Alzheimer's disease (AD) is the leading cause of dementia worldwide. Late-onset AD (LOAD), is the most common form of Alzheimer's disease, representing about $>95 \%$ of cases and early-onset $\mathrm{AD}$ represents $<5 \%$ of cases. Several risk factors have been discovered that are associated with $\mathrm{AD}$, with advancing age being the most prominent. Other environmental risk factors include diabetes mellitus, level of physical activity, educational status, hypertension and head injury. The most well known genetic risk factor for LOAD is inheritance of the apolipoprotein (apo) E4 allele. Recently, rare variants of TREM2 have been reported as a significant risk factor for LOAD, comparable to inheritance of apoE4. In this review we will focus on the role(s) of TREM2 in AD as well as in other neurodegenerative disorders.
\end{abstract}

\section{Keywords}

TREM-2; Alzheimer's disease; Fronto-temporal dementia; Nasu-hakola disease; Hereditary diffused leukoencephalopathy with spheroids; Parkinson's disease; Amyotrophic lateral sclerosis

Copyright: (C) 2014 Yaghmoor F, et al.

This is an open-access article distributed under the terms of the Creative Commons Attribution License, which permits unrestricted use, distribution, and reproduction in any medium, provided the original author and source are credited.

*Corresponding author: Thomas Wisniewski, New York University School of Medicine, Alexandria ERSP, Rm 802, 450 East 29th St. New York, NY 10016, USA, Tel: (212) 263-7993; Fax: (212) 263-7528; thomas.wisniewski@nyumc.org. 


\section{Introduction}

$\mathrm{AD}$ is the leading cause for dementia in the world, and affects an estimated 5.4 million Americans currently. This figure includes 5.2 million individuals aged $\geq 65$ years and $\sim 200,000$ individuals under the age of 65 [1]. AD is characterized by an imbalance between the production and clearance of amyloid $\beta(\mathrm{A} \beta)$ and tau proteins, which ultimately leads to the abnormal accumulation of these proteins in the form of senile plaques and neurofibrillary tangles, where aggregated forms of $A \beta$ and tau deposit, respectively [2]. Soluble oligomeric forms of $A \beta$ and tau are felt to be the most toxic species linked to the neuronal dysfunction/ death in $\mathrm{AD}$ [3]. There are two forms of $\mathrm{AD}$, the early-onset (EOAD) form, which is related to mutations in presenilin 1, presenilin 2 (PS1 and PS2) or the amyloid precursor protein (APP), when associated with autosomal dominant inheritance [4-6]. EOAD affects a minority of AD patients. Epidemiological data suggests that apparent autosomal dominant transmission is found in only $\sim 10 \%$ of all EOAD cases, leaving the genetic association of the majority of EOAD unexplained [4,7]. The other form is the sporadic late-onset form (LOAD), which afflicts $>95 \%$ of patients with AD [4-6,8,9]. Some of the known environmental risk factors for LOAD include diabetes mellitus, level of physical activity, educational status, hypertension and head injury [10]. The strongest identified genetic risk factor for LOAD is the inheritance of the apolipoprotein (apo) E4 allele [11]. Recently, rare variants of the gene encoding triggering receptor expressed on myeloid cells 2 (TREM2; located on 6p21.1) have been reported as a significant risk factor for LOAD, with an odds ratio similar to apoE4 [12]. In this review we will review the general functions and characteristics of TREM 2 and related genes, mainly focusing on their association as a risk factor for AD, as well as other central nervous system (CNS) diseases.

\section{TREM2 Overview}

TREM2 is an innate immune receptor expressed on the cell surface of microglia, macrophages, osteoclasts and immature dendritic cells [12-14]. TREM2 has also been found on bronchial epithelial cells, fibroblasts, and lung adenocarcinoma cells. The TREM2 gene encodes 5 exons that code for a $693 \mathrm{pb}$ DNA, located on chromosome 6p21.1, which is translated into 230 amino-acids [15-17]. The receptor is a variably glycosylated, single-pass type I membrane glycoprotein made up of an extracellular immunoglobulin-like domain, a transmembrane domain and a cytoplasmic tail, which associates with tyrosine kinasebinding protein (TYROBP, also known as DAP12), forming a receptor-signaling complex[18,19] (Figure 1). TREM2 is one of the highest expressed cell surface receptors on microglia and is $>300$ fold enriched in microglia versus astrocytes [20]. Microglia plays a key role in the immune response in the central nervous system (CNS) and is the resident innate immune cells responsible for the early control of infections. In the human brain, TREM 2 is found at high concentrations in white matter, the hippocampus and the neocortex, but at very low concentrations in the cerebellum. These regions are consistent with the distribution of pathology in AD [14,18,21]. TREM2 was initially identified as a phagocytic receptor of bacteria [22]. TREM2 recognizes anionic lipopolysaccharide (LPS) in the cell wall of bacteria. When the bacteria bind to TREM2 on macrophages, activation of the signaling pathway triggers the phagocytic uptake of the bacteria and the release of reactive oxygen species [23]. Heat shock protein 60 (Hsp60) is a mitochondrial chaperone that has 
also been shown to be a TREM2 agonist when expressed on the surface of neuroblastoma cells or astrocytes [24]. The formation of amyloid plaques in an AD model has been shown to induce expression of TREM2, in particular among microglia in the outer zone of plaques, correlating with partial amyloid phagocytosis [25]. TREM2 expression also correlated positively with microglia being able to stimulate CD4+ T-cell proliferation, tumor necrosis factor, but not interferon $\gamma$; hence, potentially promoting neuroprotective "wound repair responses" [25]. TREM2 has also been shown to be involved in phagocytosis of apoptotic neurons, since down regulation of TREM2 or DAP12 in microglia reduces such phagocytosis, while over expression of TREM2 has the opposite effect [26]. Other pattern recognition receptors which have been shown to play an important part in macrophage/ microglial function and have a role in $\mathrm{AD}$ related pathology are the Toll-like receptors (TLRs) [12,27-29]. TLRs interact with the TREM2/DAP12 on multiple levels; these interactions appear to be tissue and receptor specific [30,31].

In addition to its role as part of the innate immune systems response to pathogens, TREM2 is known to have anti-inflammatory properties; it suppresses inflammatory responses by repression of cytokine production and secretion [32]. TREM2 reduces macrophage activation and inhibits cytokine production in response to both TLR2 and TLR4 ligands zymosan and LPS $[33,34]$. Conversely reduction of TREM2 expression by either RNA interference or by targeted gene deletion amplified inflammatory cytokine responses by macrophages following stimulation of multiple different TLRs including TLR2, 4 and 9 [35]. Modulation of innate immunity via TLR2,4 and 9 signaling pathways has previously been shown to be critical in modulating $A \beta$ deposition. TLR4 deficient mice displayed increases of diffuse $A \beta$ and fibrillar $A \beta$ deposits compared with control mice [36], suggesting that TLR4 signaling is involved in $A \beta$ clearance [37]. Microglia deficient in TLR2, TLR4, or the co-receptor CD14 are not activated by A $\beta$ and do not show a phagocytic response [38]. Transgenic AD mice lacking TLR4 have markedly elevated levels of diffuse and fibrillar A $\beta$. Furthermore, stimulation of microglial cells with TLR2-, TLR4-, or TLR9- specific agonists accelerates $A \beta$ clearance both in vitro and in vivo [39]. We have shown that the administration of the TLR9 agonist CpG oligonucleotides (ODN) containing unmethylated $\mathrm{CpG}$ sequences to $\mathrm{AD}$ model $\mathrm{Tg} 2576$ mice induced a reduction of cortical and vascular $A \beta$ levels without apparent toxicity and improve cognitive function [40]. In addition, TLRs can affect tau related pathology; TLR4 ligand (LPS)-induced MAPT hyperphosphorylation and exacerbation of tau pathology has been well documented [41-44]. Hence it can be speculated that TREM2 has a protective role in AD pathogenesis. Its antiinflammatory properties could reduce innocent bystander neuronal damage, as well as, having a role in modulating TLR related signaling pathways that affect both $\mathrm{A} \beta$ and tau deposition $[12,16,17,23,25]$. TREM2 is also known to effect phagocytosis of damaged cells. TREM2 interacts with endogenous ligands on neurons, leading to the direct removal of damaged cells [45]. In several models of multiple sclerosis increased microglial expression of TREM2 has been shown to enhance phagocytosis and promotes a M2-like activation state of microglia, which is thought to have protective effects [46-48]. The removal of damaged or apoptotic neurons mediated via TREM2 could promote tissue repair in response to AD related pathology. This TREM2 mediated phagocytic activity also has been linked to an enhanced ability of microglia to clear $\mathrm{A} \beta$ and amyloid plaques in vitro and in $\mathrm{AD}$ model 
APP23 Tg mice [25]. The importance of TREM2 is not confined to the innate immune response to A $\beta$ pathology. A recent large GWAS study has shown that the TREM2 R47H variant has a strong association with both elevated CSF tau and hyperphosphorylated tau protein (ptau) levels [49]. This is important as numerous studies have shown that increases of ptau in CSF correlates with neuronal loss and is predictive of cognitive decline in AD [50-52]. Furthermore, neurofibrillary tangle deposition correlates better with the degree of dementia, compared to the amyloid plaque burden [2]. Microglia are well known to have the potential to acquire a broad array of cytotoxic and cytoprotective functional states $[41,48,53]$. TREM2 appears to be an important factor regulating this balance in response to $\mathrm{AD}$ associated pathology.

\section{TREM2 and the Risk for AD}

Jonsson et al. performed whole genome sequencing on 2261 Icelandic individuals and found that a rare mutation (rs75932628-T, frequency of $0.63 \%$ ), predicted to result in a TREM2 $\mathrm{R} 47 \mathrm{H}$ substitution, was associated with an increased risk of AD (odds ratio 2.92). Subsequently this association was replicated in cohorts from the USA, Germany, the Netherlands and Norway [18]. Concurrently, Guerreiro et al. confirmed the link between LOAD and the R47H variant by meta-analysis of three imputed data sets of genome-wide association studies (EADI, GERAD and ANM) [19]. They also found six additional variants (Q33X, Y38C, T66M, D87D, R98W and H157Y) that were present in affected cases and not in controls, which could be related to AD pathology. Three of these variants (Q33X, Y38C and $\mathrm{T} 66 \mathrm{M}$ ) had been previously reported in the homozygous state to be associated with a frontotemporal dementia like syndrome [54]. A replication study conducted in a Spanish population confirmed the variant to be associated with a higher risk for LOAD, as well as, EOAD, with $\mathrm{R} 47 \mathrm{H}$ found exclusively in $1.4 \%$ of $\mathrm{AD}$ cases.

T66M, Y38C, and Q33X homozygous variants have also previously been observed in NasuHakola Disease (NHD) and are strongly suspected to result in TREM2 loss-of- function [19].

The $\mathrm{R} 47 \mathrm{H}$ variant has a minor allele frequency (MAF) of $0.63 \%$ in Icelanders, $0.26 \%$ in European Americans, and 0.2\% in African Americans[18]. Another research group in France confirmed the association between AD with the TREM2 R47H substitution variant (rs75932628-T), located within the extracellular immunoglobulin-like domain-mutation [55]. This study's sample included 726 EOAD and 783 controls. The effect size was similar to the reports discussed above for TREM2 in LOAD, suggesting that the role of TREM2 on AD pathology is not critically dependent on aging. Molecular dynamics simulations have suggested that the R27H substitution could have significant effects on ligand binding affinity, as well as the structural configuration of TREM2 [56]. Assuming that the TREM2 risk variant impairs TREM2 function, it is strongly believed that it does so by decreasing affinity of TREM2 to its natural ligands. This will in turn decrease its downstream effect. This suggests that reduced function of TREM-2 causes reduced phagocytic clearance of amyloid proteins or cellular debris. This then impairs the protective mechanism in the brain, ultimately leading to the abnormal accumulation of tau and beta-amyloid, the hallmark of AD. 
A recent study has also shown that TREM2 undergoes sequential proteolytic processing by ectodomain shedding and intramembrane proteolysis [57]. The latter cleavage is by $\gamma-$ secretase, which is the enzyme that also cleaves the amyloid precursor protein to release $A \beta$ [58]. Inhibition of $\gamma$-secretase produces an accumulation of TREM 2 carboxyl terminal fragments at the cell surface, trapping its adaptor DAP12, and resulting in impairment of TREM2 signaling [57]. The $\gamma$-secretase complex contains either PS1 or PS2 as the catalytically active component, with mutations in PS1/2 being the most common cause of EOAD $[6,59]$. These findings provide another link between TREM2 and pathways involved in AD pathology.

\section{The TREM Family and a Missense Variant Protective against Alzheimer's Disease}

TREM2 belongs to a family of structural related genes clustered on human chromosome 6p21.1 and mouse chromosome 17C. These include TREM1, TREM2, and TREM3, as well as "TREM-like" genes: TREML1 and TREML2 [60-62]. The first to be discovered was TREM1 which has been established as an amplifier of systemic inflammatory responses $[15,62]$. This contrasts with the role of TREM 2 which has emerged as a negative regulator of autoimmunity [61,62]. An AD association GWAS had identified an inter-genic SNP [rs9381040] located $5.5 \mathrm{~Kb}$ downstream from TREML2 and $24 \mathrm{~Kb}$ upstream from TREM2 [63]. A recent exome-sequencing study of 16,254 cases and 20,052 controls suggest a TREML2 coding missense variant $\mathrm{p} . \mathrm{S} 144 \mathrm{G}$ as the driver of the latter GWAS signal, which is independent of the TREM2 R47H loci [64]. This variant is associated with a reduced risk for $\mathrm{AD}$ [OR=0.91; $\mathrm{CI}=0.86-0.97$ ] [64]. TREM 2 and TREML2 appear to have opposing roles in their modulation of innate immunity. Treatment of microglia with IL-1 $\beta$ represses expression of TREM2, while increasing expressing of TREML2 [64]. Unlike TREM2, TREML2 signal is not coupled to DAP12 and it appears to play a pro-inflammatory role [61,64]. Hence different missense variants in the TREM family can either enhance AD pathology or inhibit it; highlighting the importance of innate immunity modulation in the pathogenesis of $\mathrm{AD}$.

\section{TREM 2 and Other CNS Diseases}

\section{Nasu-Hakola Disease: Polycystic lipomembranous osteodysplasia with sclerosing leukoencephalopathy}

Homozygous TREM-2 mutations that cause a near-complete functional loss of the TREM-2 gene (e.g. p.Q33X) or TYROBP/DAP12 have been known to be linked to an autosomal recessive disorder called polycystic lipomembranous osteodysplasia with sclerosing leukoencephalopathy (PLOSL), also known as Nasu-Hakola Disease [65-67]. Over 200 cases have been reported worldwide in the literature, the majority of them being in the Japanese and Finnish population. The prevalence in Finland is estimated between 1/500,000 and $1 / 1,000,000$. This fatal disease is characterized by manifestations affecting both bones and brain suggesting that the function of TREM-2 is similar in both systems. Patients with (PLOSL) have progressive presenile inflammatory neurodegeneration that leads to dementia and formation of multifocal bone cysts predisposing to pathological fracture. In addition, 
these patients often have psychiatric symptoms in the second decade of life, followed by severe frontotemporal dementia with premature death in the fourth or fifth decade of life. PLOSL patients have not been reported to have AD amyloid plaques, indicating that dysfunctional neuroinflammation can be an amyloid independent pathway leading to dementia [23]. Patients with heterozygous loss-of-function mutations carry a higher risk for age associated cognitive loss and/or LOAD [19,54,66,68]. Three TREM2 variants previously linked in the homozygous state to either PLOSL or FTD (e.g. p.T66M, p.Y38C, and p.Q33X) have been shown to be associated with LOAD. Conversely, the R47H mutation has also been reported in patients with PLOSL suggesting similar neuroinflammatory mechanisms may mediate neuronal dysfunction/death in AD and PLOSL, in association with amyloid deposition or in its absence, respectively [19].

\section{Hereditary Diffuse Leukoencephalopathy with Spheroids}

The colony-stimulating factor 1 receptor (CSF1R) is located on microglia. It binds CSF1 and like TREM2 co-signals through DAP12. Patients with a partial loss-of-function of this gene develop a neurodegenerative disease called hereditary diffuse leukoencephalopathy with spheroids (HDLS) [69]. This autosomal dominant disease is characterized by the degeneration of white matter predominantly in the frontal lobes and corpus callosum, with subsequent cortical atrophy [70,71]. The clinical manifestations are variable and can include behavioral changes, dementia, depression, parkinsonism, ataxia, pyramidal signs, and seizures [70,71]. Neuropathologically there is widespread myelin and axonal destruction, in association with axonal swellings called spheroids, as well as characteristic pigmented macrophages [70,71]. The swelling in the axons resemble, to some extent, those produced by shear stress in closed head injuries with damaged axons. A number of different loss of function mutations in CSF1R have been reported, with in vitro studies suggesting that patients with $50 \%$ of the normal protein will manifest the disease [72]. It has been speculated that impaired CSF1R mediated microglial repair of axonal degeneration is the mechanism underlying HDLS [71,72]. Hence dysfunction of the innate immune complex consisting of TREM2, CSF1R and the signaling molecule DAP12 in microglia can lead to chronic neurodegeneration, with variable clinical and pathological phenotypes.

\section{Parkinson's disease, Frontotemporal Dementia and Amyotrophic Lateral Sclerosis}

Parkinson's disease (PD), frontotemporal dementia (FTD) and amyotrophic lateral sclerosis (ALS), similar to $\mathrm{AD}$, all belong to the category of conformational neurodegenerative disorders where normal self-proteins aggregate forming toxic $\beta$-sheet rich intracellular inclusions or extracellular amyloid deposits $[3,74]$. The most toxic species of the different aggregates are felt to be oligomers, which in some cases can spread using a prion like mechanism $[3,75]$. In PD a-synuclein aggregates forming oligomers and Lewy bodies, while in different forms of FTD tau, TAR-DNA-binding protein-43 (TDP-43) or fused in sarcoma (FUS) can aggregate[73,76]. In different forms of ALS, SOD1, TDP-43 or FUS form toxic aggregates [77]. Microgliosis is a critical part of each of these disorders and the activation state of microglia can result in either pathology enhancement or amelioration [53]. TREM2 variants have recently been associated with each of these disorders. In PD the R47H 
TREM2 variant was first found to be associated when patient populations were screened in the USA and Spain [78]. A subsequent study has confirmed the association of the R47H variant to PD with an odd ratio of 2.67 [79]. TREM2 variants are also associated with a FTD phenotype. Besides the association of TREM2 variants with PLOSL, a homozygous deletion of the consensus donor splice site in intron 1 of TREM 2 was reported in a Lebanese family with typical behavioral FTD with no bone involvement [80]. A typical autosomal recessive FTD phenotype has also been associated with a p.Y198X TREM2 mutation in a Columbian family [81]. Additional studies have reported an association with a FTD phenotype and the R47H TREM2 variant, with the frequency of the variant being $\sim$ three fold over represented among FTD patients, with an odds ratio of 5.06 [79,82]. A recent study has also shown a link between the R47H TREM2 variant and ALS [83].

\section{Conclusions}

Studies conducted over 20 years ago had suggested the potential critical role of microglia for both the formation and clearance of amyloid lesions in $\mathrm{AD}(84-86)$. Interest in the importance of innate immunity modulating neurodegeneration has been greatly increased by recent GWAS studies that have linked genes such as CR1, CD33 and MS4A4A/MS4A6A that are associated with microglial function to $\mathrm{AD}[87,88]$. Numerous studies on the relationship of TLRs to AD have shown that modification of these signaling pathways can have profound effects on AD related pathology, through modification of the inflammatory state of microglia/macrophages. Our own studies have shown that appropriate stimulation of innate immunity via TLR 9 can ameliorate both $A \beta$ and tau related pathology $[12,40,89]$. Recent studies, outlined above, have linked TREM2 variants to most of the different types of conformational neurodegenerative disorders. These studies indicate that modification of microglial function in neurodegeneration is a critical therapeutic target.

\section{Acknowledgements}

This manuscript was supported by NIH grants NS073502, AG20245 and AG08051, as well as the Saudi Arabia Cultural Mission (USA).

\section{References}

1. 2012 Alzheimer's disease facts and figures. 2012 Online Source.

2. Nelson PT, Alafuzoff I, Bigio EH, Bouras C, Braak H, Cairns N, Davies P, Tredici KD, Duyckaerts C, Frosch MP, Hof PR, Hulette C, Hyman BT, Iwatsubo T, Jellinger KA, Jicha GA, Kovari E, Kukull WA, Leverenz JB, Love S, Mackenzie IR, Mann DM, Masliah E, McKee A, Montine TJ, Morris JC, Schneider JA, Sonnen JA, Thal DR, Trojanowski JQ, Troncoso JC, Wisniewski T, Woltjer RL, Beach TG. Correlation of Alzheimer's disease neuropathologic changes with cognitive status: a review of the literature. Journal of Neuropathology and Experimental Neurology. 2012; 71:362-381. [PubMed: 22487856]

3. Lesné SE. Breaking the Code of Amyloid- $\beta$ Oligomers. Int J Cell Biol. 2013; 2013:950783. [PubMed: 24072999]

4. Guerreiro R, Hardy J. Genetics of Alzheimer's Disease. Neurotherapeutics. 2014; 11(4):732-737. [PubMed: 25113539]

5. Karch CM, Cruchaga C, Goate AM2. Alzheimer's disease genetics: from the bench to the clinic. Neuron. 2014; 83:11-26. [PubMed: 24991952] 
6. Bertram L, Tanzi RE. The genetics of Alzheimer's disease. Prog Mol Biol Transl Sci. 2012; 107:79-100. [PubMed: 22482448]

7. Wingo TS, Lah JJ, Levey AI, Cutler DJ. Autosomal recessive causes likely in early-onset Alzheimer disease. Arch Neurol. 2012; 69:59-64. [PubMed: 21911656]

8. Kim DH, Yeo SH, Park JM, Choi JY, Lee TH, et al. Genetic markers for diagnosis and pathogenesis of Alzheimer's disease. Gene. 2014; 545:185-193. [PubMed: 24838203]

9. Bruni AC, Conidi ME, Bernardi L. Genetics in degenerative dementia: current status and applicability. Alzheimer Dis Assoc Disord. 2014; 28:199-205. [PubMed: 24805970]

10. Di Marco LY, Marzo A, Muñoz-Ruiz M, Ikram MA, Kivipelto M, et al. Modifiable lifestyle factors in dementia: a systematic review of longitudinal observational cohort studies. J Alzheimers Dis. 2014; 42:119-135. [PubMed: 24799342]

11. Potter H, Wisniewski T. Apolipoprotein e: essential catalyst of the Alzheimer amyloid cascade. Int J Alzheimers Dis. 2012; 2012:489428. [PubMed: 22844635]

12. Boutajangout A, Wisniewski T. The innate immune system in Alzheimer's disease. Int J Cell Biol. 2013; 2013:576383. [PubMed: 24223593]

13. Colonna M. TREMs in the immune system and beyond. Nat Rev Immunol. 2003; 3:445-453. [PubMed: 12776204]

14. Singaraja RR. TREM2: a new risk factor for Alzheimer's disease. Clin Genet. 2013; 83:525-526. [PubMed: 23347262]

15. Bouchon A, Dietrich J, Colonna M. Cutting edge: inflammatory responses can be triggered by TREM-, a novel receptor expressed on neutrophils and monocytes. J Immunol. 2000; 164:49914995. [PubMed: 10799849]

16. Jiang T, Yu JT, Zhu XC, Tan L. TREM2 in Alzheimer's disease. Molecular Neurobiology. 2013

17. Golde TE, Streit WJ, Chakrabarty P. Alzheimer's disease risk alleles in TREM2 illuminate innate immunity in Alzheimer's disease. Alzheimers Res Ther. 2013; 5:24. [PubMed: 23692967]

18. Jonsson T, Stefansson H, Steinberg S, Jonsdottir I, Jonsson PV, et al. Variant of TREM2 associated with the risk of Alzheimer's disease. N Engl J Med. 2013; 368:107-116. [PubMed: 23150908]

19. Guerreiro R, Wojtas A, Bras J, Carrasquillo M, Rogaeva E, et al. TREM2 variants in Alzheimer's disease. N Engl J Med. 2013; 368:117-127. [PubMed: 23150934]

20. Hickman SE, Kingery ND, Ohsumi TK, Borowsky ML, Wang LC, et al. The microglial sensome revealed by direct RNA sequencing. Nat Neurosis. 2013; 16:1896-1905.

21. Sun GY, Guan CX, Zhou Y, Liu YP, Li SF, et al. Vasoactive intestinal peptide re-balances TREM-1/TREM-2 ratio in acute lung injury. Regul Pept. 2011; 167:56-64. [PubMed: 21130121]

22. N'Diaye EN, Branda CS, Branda SS, Nevarez L, Colonna M, et al. TREM-2 (triggering receptor expressed on myeloid cells 2) is a phagocytic receptor for bacteria. J Cell Biol. 2009; 184:215223. [PubMed: 19171755]

23. Neumann H, Daly MJ. Variant TREM2 as risk factor for Alzheimer's disease. N Engl J Med. 2013; 368:182-184. [PubMed: 23151315]

24. Stefano L, Racchetti G, Bianco F, Passini N, Gupta RS, et al. The surface-exposed chaperone, Hsp60, is an agonist of the microglial TREM2 receptor. J Neurochem. 2009; 110:284-294. [PubMed: 19457124]

25. Melchior B, Garcia AE, Hsiung BK, Lo KM, Doose JM, et al. Dual induction of TREM2 and tolerance-related transcript, Tmem176b, in amyloid transgenic mice: implications for vaccinebased therapies for Alzheimer's disease. ASN Neuro. 2010; 2:e00037. [PubMed: 20640189]

26. Takahashi K, Rochford CD, Neumann H. Clearance of apoptotic neurons without inflammation by microglial triggering receptor expressed on myeloid cells-2. J Exp Med. 2005; 201:647-657. [PubMed: 15728241]

27. Arroyo DS, Soria JA, Gaviglio EA, Rodriguez-Galan MC, Iribarren P. Toll-like receptors are key players in neurodegeneration. Int Immunopharmacol. 2011; 11:1415-1421. [PubMed: 21616174]

28. Hanke ML, Kielian T. Toll-like receptors in health and disease in the brain: mechanisms and therapeutic potential. Clin Sci (Lond). 2011; 121:367-387. [PubMed: 21745188] 
29. Drouin-Ouellet J, Cicchetti F. Inflammation and neurodegeneration: the story 'retolled'. Trends Pharmacol Sci. 2012; 33:542-551. [PubMed: 22944460]

30. Paradowska-Gorycka A, Jurkowska M. Structure, expression pattern and biological activity of molecular complex TREM-2/DAP12. Hum Immunol. 2013; 74:730-737. [PubMed: 23459077]

31. Akira S. TLR signaling. Curr Top Microbiol Immunol. 2006; 311:1-16. [PubMed: 17048703]

32. Sessa G, Podini P, Mariani M, Meroni A, Spreafico R, Sinigaglia F, Colonna M, Panina P, Meldolesi J. Distribution and signaling of TREM2/DAP1, the receptor system mutated in human polycystic lipomembraneousosteodysplasia with sclerosing leukoencephalopathy dementia. European Journal of Neuroscience. 2004; 20:2617-2628. [PubMed: 15548205]

33. Hamerman JA, Jarjoura JR, Humphrey MB, Nakamura MC, Seaman WE, et al. Cutting edge: inhibition of TLR and FcR responses in macrophages by triggering receptor expressed on myeloid cells (TREM)-2 and DAP12. J Immunol. 2006; 177:2051-2055. [PubMed: 16887962]

34. Turnbull IR, Gilfillan S, Cella M, Aoshi T, Miller M, et al. Cutting edge: TREM-2 attenuates macrophage activation. J Immunol. 2006; 177:3520-3524. [PubMed: 16951310]

35. Hamerman JA, Tchao NK, Lowell CA, Lanier LL. Enhanced Toll-like receptor responses in the absence of signaling adaptor DAP12. Nat Immunol. 2005; 6:579-586. [PubMed: 15895090]

36. Tahara K, Kim HD, Jin JJ, Maxwell JA, Li L, et al. Role of toll-like receptor signalling in Abeta uptake and clearance. Brain. 2006; 129:3006-3019. [PubMed: 16984903]

37. Jin JJ, Kim HD, Maxwell JA, Li L, Fukuchi K. Toll-like receptor 4-dependent upregulation of cytokines in a transgenic mouse model of Alzheimer's disease. J Neuroinflammation. 2008; 5:23. [PubMed: 18510752]

38. Reed-Geaghan EG, Savage JC, Hise AG, Landreth GE. CD14 and toll-like receptors 2 and 4 are required for fibrillarA \{beta\}-stimulated microglial activation. J Neurosci. 2009; 29:11982-11992. [PubMed: 19776284]

39. Michaud JP, Halle M, Lampron A, Theriault P, Prefontaine P, Filali M, Tribout-Jover P, Lanteigne AM, Jodoin R, Cluff C, Brichard V, Palmantier R, Pilorget A, Larocque D, Rivest S. Toll-like receptor 4 stimulation with the detoxified ligand monophosphoryl lipid A improves Alzheimer's disease-related pathology. Proc. Natl. Acad. Sci. U.S.A. 2013; 110:1941-1946. [PubMed: 23322736]

40. Scholtzova H, Kascsak RJ, Bates KA, Boutajangout A, Kerr DJ, et al. Induction of toll-like receptor 9 signaling as a method for ameliorating Alzheimer's disease-related pathology. J Neurosci. 2009; 29:1846-1854. [PubMed: 19211891]

41. Lee DC, Rizer J, Hunt JB, Selenica ML, Gordon MN, et al. Review: experimental manipulations of microglia in mouse models of Alzheimer's pathology: activation reduces amyloid but hastens tau pathology. Neuropathology and Applied Neurobiology. 2013; 39:69-85. [PubMed: 23171029]

42. Bhaskar K, Konerth M, Kokiko-Cochran ON, Cardona A, Ransohoff RM, et al. Regulation of tau pathology by the microglial fractalkine receptor. Neuron. 2010; 68:19-31. [PubMed: 20920788]

43. Lee DC, Rizer J, Selenica ML, Reid P, Kraft C, et al. LPS- induced inflammation exacerbates phospho-tau pathology in rTg4510 mice. J Neuroinflammation. 2010; 7:56. [PubMed: 20846376]

44. Kitazawa M, Cheng D, Tsukamoto MR, Koike MA, Wes PD, et al. Blocking IL-1 signaling rescues cognition, attenuates tau pathology, and restores neuronal beta-catenin pathway function in an Alzheimer's disease model. Journal of Immunology. 2011; 187:6539-6549.

45. Hsieh CL, Koike M, Spusta SC, Niemi EC, Yenari M, et al. A role for TREM2 ligands in the phagocytosis of apoptotic neuronal cells by microglia. J Neurochem. 2009; 109:1144-1156. [PubMed: 19302484]

46. Takahashi K, Prinz M, Stagi M, Chechneva O, Neumann H. TREM2-transduced myeloid precursors mediate nervous tissue debris clearance and facilitate recovery in an animal model of multiple sclerosis. PLoS Med. 2007; 4:e124. [PubMed: 17425404]

47. Piccio L, Buonsanti C, Mariani M, Cella M, Gilfillan S, et al. Blockade of TREM-2 exacerbates experimental autoimmune encephalomyelitis. Eur. J Immunol. 2007; 37:1290-1301. [PubMed: 17407101]

48. Varnum MM, Ikezu T. The classification of microglial activation phenotypes on neurodegeneration and regeneration in Alzheimer's disease brain. Arch Immunol Ther Exp (Warsz). 2012; 60:251-266. [PubMed: 22710659] 
49. Cruchaga C, Kauwe JS, Harari O, Jin SC, Cai Y, et al. GWAS of cerebrospinal fluid tau levels identifies risk variants for Alzheimer's disease. Neuron. 2013; 78:256-268. [PubMed: 23562540]

50. Blennow K, Hampel H. CSF markers for incipient Alzheimer's disease. Lancet Neurol. 2003; 2:605-613. [PubMed: 14505582]

51. Hampel H, Buerger K, Zinkowski R, Teipel SJ, Goernitz A, et al. Measurement of phosphorylated tau epitopes in the differential diagnosis of Alzheimer disease: a comparative cerebrospinal fluid study. Arch. Gen. Psychiatry. 2004; 61:95-102. [PubMed: 14706948]

52. Andersson C, Blennow K, Almkvist O, Andreasen N, Engfeldt P, et al. Increasing CSF phosphotau levels during cognitive decline and progression to dementia. Neurobiol Aging. 2008; 29:14661473. [PubMed: 17512092]

53. Gentleman SM. Review: microglia in protein aggregation disorders: friend or foe? Neuropathol Appl Neurobiol. 2013; 39:45-50. [PubMed: 23339288]

54. Guerreiro RJ, Lohmann E, Brás JM, Gibbs JR, Rohrer JD, et al. Using exome sequencing to reveal mutations in TREM2 presenting as a frontotemporal dementia-like syndrome without bone involvement. JAMA Neurol. 2013; 70:78-84. [PubMed: 23318515]

55. Pottier C, Wallon D, Rousseau S, Rovelet-Lecrux A, Richard AC, et al. TREM2 R47H variant as a risk factor for early-onset Alzheimer's disease. J Alzheimers Dis. 2013; 35:45-49. [PubMed: 23380991]

56. Abduljaleel Z, Al-Allaf FA, Khan W, Athar M, Shahzad N, et al. Evidence of trem2 variant associated with triple risk of Alzheimer's disease. PLoS One. 2014; 9:e92648. [PubMed: 24663666]

57. Wunderlich P, Glebov K, Kemmerling N, Tien NT, Neumann H, et al. Sequential proteolytic processing of the triggering receptor expressed on myeloid cells-2 (TREM2) protein by ectodomain shedding and gamma-secretase-dependent intramembranous cleavage. Journal of Biological Chemistry. 2013; 288:33027-33036. [PubMed: 24078628]

58. Golde TE, Koo EH, Felsenstein KM, Osborne BA, Miele L. $\hat{\mathrm{I}}^{3}$-Secretase inhibitors and modulators. Biochim Biophys Acta. 2013; 1828:2898-2907. [PubMed: 23791707]

59. Selkoe DJ, Wolfe MS. Presenilin: running with scissors in the membrane. Cell. 2007; 131:215221. [PubMed: 17956719]

60. Klesney-Tait J, Turnbull IR, Colonna M. The TREM receptor family and signal integration. Nat Immunol. 2006; 7:1266-1273. [PubMed: 17110943]

61. Ford JW, McVicar DW. TREM and TREM-like receptors in inflammation and disease. Curr Opin Immunol. 2009; 21:38-46. [PubMed: 19230638]

62. Pelham CJ, Agrawal DK. Emerging roles for triggering receptor expressed on myeloid cells receptor family signaling in inflammatory diseases. Expert Rev Clin Immunol. 2014; 10:243-256. [PubMed: 24325404]

63. Lambert JC, Ibrahim-Verbaas CA, Harold D, Naj AC, Sims R, et al. Meta-analysis of 7,046 individuals identifies 11 new susceptibility loci for Alzheimer's disease. Nat. Genet. 2013; 45:1452-1458. [PubMed: 24162737]

64. Benitez BA, Jin SC, Guerreiro R, Graham R, Lord J, et al. Missense variant in TREML2 protects against Alzheimer's disease. Neurobiology of Aging. 2014; 35:1510-1526. [PubMed: 24439484]

65. Paloneva J, Kestilä M, Wu J, Salminen A, Böhling T, et al. Loss-of-function mutations in TYROBP (DAP12) result in a presenile dementia with bone cysts. Nat Genet. 2000; 25:357-361. [PubMed: 10888890]

66. Soragna D, Papi L, Ratti MT, Sestini R, Tupler R, et al. An Italian family affected by Nasu-Hakola disease with a novel genetic mutation in the TREM2 gene. J Neurol Neurosurg Psychiatry. 2003; 74:825-826. [PubMed: 12754369]

67. Klünemann HH, Ridha BH, Magy L, Wherrett JR, Hemelsoet DM, et al. The genetic causes of basal ganglia calcification, dementia, and bone cysts: DAP12 and TREM2. Neurology. 2005; 64:1502-1507. [PubMed: 15883308]

68. Montalbetti L, Ratti MT, Greco B, Aprile C, Moglia A, et al. Neuropsychological tests and functional nuclear neuroimaging provide evidence of subclinical impairment in Nasu-Hakola disease heterozygotes. Funct. Neurol. 2005; 20:71-75. [PubMed: 15966270] 
69. Rademakers R, Baker M, Nicholson AM, Rutherford NJ, Finch N, et al. Mutations in the colony stimulating factor 1 receptor (CSF1R) gene cause hereditary diffuse leukoencephalopathy with spheroids. Nat. Genet. 2012; 44:200-205. [PubMed: 22197934]

70. Wider C, Van Gerpen JA, De Armond S, Shuster EA, Dickson DW, et al. Leukoencephalopathy with spheroids (HDLS) and pigmentary leukodystrophy (POLD): a single entity? Neurology. 2009; 72:1953-1959. [PubMed: 19487654]

71. Wider C, Wszolek ZK. Hereditary diffuse leukoencephalopathy with axonal spheroids: more than just a rare disease. Neurology. 2014; 82:102-103. [PubMed: 24336229]

72. Konno T, Tada M, Tada M, Koyama A, Nozaki H, et al. Haploinsufficiency of CSF-1R and clinicopathologic characterization in patients with HDLS. Neurology. 2014; 82:139-148. [PubMed: 24336230]

73. Jellinger KA. Neuropathology of Dementia Disorders. J. Alz. Dis. Parkinsonism. 2014; 4:135.

74. Wisniewski T, Goñi F2. Immunotherapy for Alzheimer's disease. Biochem Pharmacol. 2014; 88:499-507. [PubMed: 24412277]

75. Walker LC, Diamond MI, Duff KE, Hyman BT. Mechanisms of protein seeding in neurodegenerative diseases. JAMA Neurol. 2013; 70:304-310. [PubMed: 23599928]

76. Riedl L, Mackenzie IR, Förstl H, Kurz A, Diehl-Schmid J. Frontotemporal lobar degeneration: current perspectives. Neuropsychiatr Dis Treat. 2014; 10:297-310. [PubMed: 24600223]

77. Al-Chalabi A, Jones A, Troakes C, King A, Al-Sarraj S, et al. The genetics and neuropathology of amyotrophic lateral sclerosis. Acta Neuropathol. 2012; 124:339-352. [PubMed: 22903397]

78. Benitez BA, Cruchaga C. United States-Spain Parkinson's Disease Research Group. TREM2 and neurodegenerative disease. N Engl J Med. 2013; 369:1567-1568. [PubMed: 24131187]

79. Rayaprolu S, Mullen B, Baker M, Lynch T, Finger E, et al. TREM2 in neurodegeneration: evidence for association of the p.R47H variant with frontotemporal dementia and Parkinson's disease. Mol. Neurodegener. 2013; 8:19. [PubMed: 23800361]

80. Chouery E, Delague V, Bergougnoux A, Koussa S, Serre JL, et al. Mutations in TREM2 lead to pure early-onset dementia without bone cysts. Hum Mutat. 2008; 29:E194-E204. [PubMed: 18546367]

81. Giraldo M, Lopera F, Siniard L, Corneveaux JJ, Schrauwen I, Carvajal J, Munoz C, RamirezRestrepo M, Gaiteri C, Myers AJ, Caselli RJ, Kosik KS, Reiman EM, Huentelman MJ. Variants in triggering receptor expressed on myeloid cells 2 are associated with both behavioral variant frontotemporal lobar degeneration and Alzheimer's disease. Neurobiol. Aging. 2013; 34:20772078. [PubMed: 23582655]

82. Cuyvers E, Bettens K, Philtjens S, Van Langenhove T, Gijselinck I, et al. Investigating the role of rare heterozygous TREM2 variants in Alzheimer's disease and frontotemporal dementia. Neurobiol Aging. 2014; 35:726. [PubMed: 24119542]

83. Cady J, Koval ED, Benitez BA, Zaidman C, Jockel-Balsarotti J, et al. TREM2 variant p.R47H as a risk factor for sporadic amyotrophic lateral sclerosis. JAMA Neurol. 2014; 71:449-453. [PubMed: 24535663]

84. Wisniewski HM, Wegiel J, Wang KC, Lach B. Ultrastructural studies of the cells forming amyloid in the cortical vessel wall in Alzheimer's disease. Acta Neuropathol. 1992; 84:117-127. [PubMed: 1381856]

85. Frackowiak J, Wisniewski HM, Wegiel J, Merz GS, Iqbal K, et al. Ultrastructure of the microglia that phagocytose amyloid and the microglia that produce beta-amyloid fibrils. Acta Neuropathol. 1992; 84:225-233. [PubMed: 1414275]

86. Wisniewski HM, Wegiel J. The role of microglia in amyloid fibril formation. Neuropathol Appl Neurobiol. 1994; 20:192-194. [PubMed: 8072658]

87. Shi H, Belbin O, Medway C, Brown K, Kalsheker N, et al. Genetic variants influencing human aging from late-onset Alzheimer's disease (LOAD) genome-wide association studies (GWAS). Neurobiol Aging. 2012; 33:1849. [PubMed: 22445811]

88. Hardy J, Bogdanovic N, Winblad B, Portelius E, Andreasen N, et al. Pathways to Alzheimer's disease. J Intern Med. 2014; 275:296-303. [PubMed: 24749173] 
89. Scholtzova H, Chianchiano P, Pan J, Sun Y, Goñi F, et al. Amyloid $\beta$ and Tau Alzheimer's disease related pathology is reduced by toll-like receptor 9 stimulation. Acta Neuropathol Commun. 2014; 2:101. [PubMed: 25178404] 


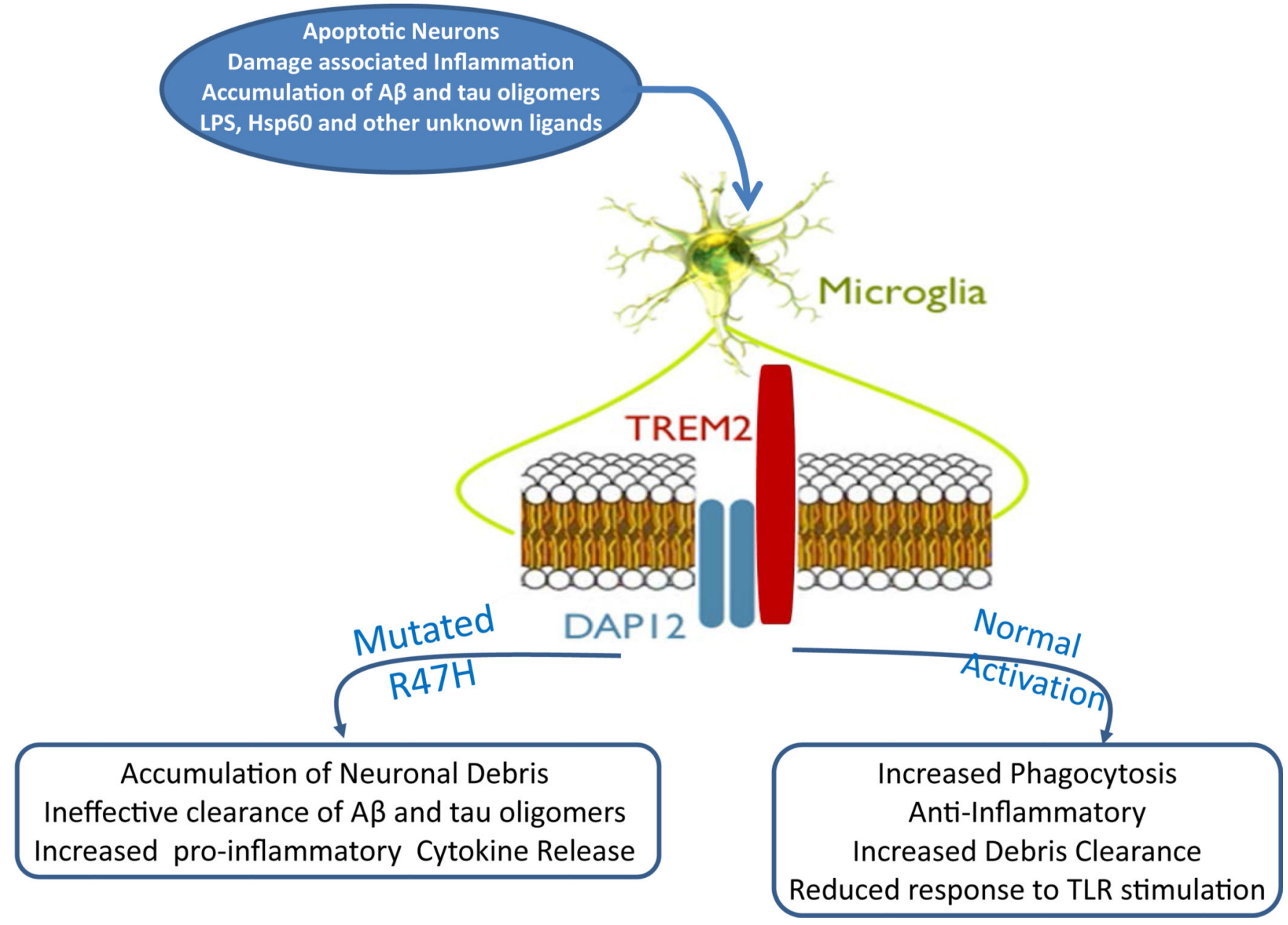

Figure 1.

Normal and disease associated pathways of TREM2 activation. 